\title{
Pheochromocytoma and Paraganglioma Clinical Distant Metastasis TNM Finding v8
}

National Cancer Institute

\section{Source}

National Cancer Institute. Pheochromocytoma and Paraganglioma Clinical Distant

Metastasis TNM Finding v8. NCI Thesaurus. Code C141107.

A clinical finding about one or more characteristics of pheochromocytoma and paragang lioma, following the rules of the TNM AJCC v8 classification system as they pertain to distant metastases. 